\title{
Prognostic Factors of the Lethality of Stroke at the Sourô Sanou University Teaching Hospital of Burkina Faso
}

\author{
Hervé B.N. Kpoda ${ }^{a}$ Léon G.B. Savadogo ${ }^{b, c}$ Délwendé R.S. Samadoulougou ${ }^{a, b}$ \\ Isidore T. Traoréa ${ }^{a, c}$ Serge M.A. Somda ${ }^{a, c}$ Daniel Lemogoum ${ }^{d}$ Issiaka Sombiéb,c \\ Athanase Millogo $^{b}$ Michèle Dramaix ${ }^{e}$ Philippe Donnen ${ }^{e}$ \\ ${ }^{a}$ Centre MURAZ Research Institute/National Institute of Public Health, Bobo-Dioulasso, Burkina Faso; bSourô Sanou \\ University Teaching Hospital, Bobo-Dioulasso, Burkina Faso; 'Public Health Department, NAZI BONI University, \\ Bobo-Dioulasso, Burkina Faso; dUniversité Libre de Bruxelles-Erasme Hospital, Bruxelles, Belgium; ' $S c h o o l$ of Public \\ Health, Université Libre de Bruxelles, Bruxelles, Belgium
}

\section{Keywords}

Stroke $\cdot$ Prognosis $\cdot$ Adult $\cdot$ Burkina Faso

\begin{abstract}
Introduction: Stroke is a major public health concern. It is a frequent pathology, $80 \%$ of which is of ischemic origin. Approximately $86 \%$ of all stroke deaths worldwide occur in lowand middle-income countries. The objective of this study was to investigate prognostic factors for in hospital lethality of stroke cases admitted in a public university hospital in Burkina Faso. Methods: This was a retrospective cohort study with a descriptive and analytical aim on adults admitted for a stroke confirmed by a brain scan at the Sourô Sanou University Teaching Hospital (CHUSS) of Bobo-Dioulasso over the period from January 1, 2009, to December 31, 2013. Results: The proportion of cases confirmed by the brain CT scan was $32 \%$ of all patients admitted for stroke in the CHUSS. The overall case fatality was $27.6 \%$. This lethality was more pronounced in patients with hemorrhagic stroke (35.8\%) compared to patients with ischemic stroke (22.4\%). Median survival was higher in patients with ischemic stroke than those with hemorrhagic one ( 36 and 25 days, respectively) with a statistically significant difference ( $p$ value $=0.001)$. In
\end{abstract}

Karger@karger.com www.karger.com/cee

Karger ${ }^{\prime}$ '

GOPEN ACCESS
(C) 2022 The Author(s)

Published by S. Karger AG, Basel

This is an Open Access article licensed under the Creative Commons Attribution-NonCommercial-4.0 International License (CC BY-NC) (http://www.karger.com/Services/OpenAccessLicense), applicable to the online version of the article only. Usage and distribution for commercial purposes requires written permission. multivariate analysis and hemorrhagic stroke (hazard ratio [HR]: 2.25; Cl 95\%: 1.41-3.61), an altered state of consciousness (HR: 1.90; Cl 95\%: 1.20-2.99) and the presence of central facial paralysis (HR: 1.67; Cl 95\%: 1.04-2.67) are factors that increased significantly the lethality. Conclusion: The study has identified three prognostic factors of lethality that are the hemorrhagic stroke type, the altered state of consciousness, and the central facial paralysis. Given the high case fatality, it is important to develop and implement effective prevention and management strategies adapted to the resources for the optimal control of stroke in Africa.

(c) 2022 The Author(s).

Published by S. Karger AG, Basel

\section{Introduction}

Strokes are becoming increasingly frequent and represent a real public health problem worldwide. In contrast to high-income countries where stroke mortality rates have declined, the burden of stroke incidence, prevalence, and mortality in low- and middle-income countries such as sub-Saharan Africa (SSA) countries have increased in recent years. This trend is expected to accelerate $[1,2]$. Globally, approximately $86 \%$ of all stroke deaths occur in 
low- and middle-income countries [2, 3]. Hospital-based studies show high proportions of stroke cases among all hospitalized patients [4]. A systematic review of community-based studies found an annual stroke incidence of 316 per 100,000 inhabitants and a prevalence reaching 981 per 100,000 inhabitants in Africa [2, 5]. Most hospital-based studies show a high risk of death due to stroke in SSA [4]. Sarfo et al. [6] reported an overall inhospital fatality rate for stroke in Ghana of 43.4\%. In Mozambique, a hospital-based study found that 217 out of 651 patients admitted for stroke died during hospitalization, giving a case fatality of $33.3 \%$, and 277 died 28 days after the event, giving a case fatality of $39.6 \%$ [7]. Factors associated with death were advanced age, low socioeconomic status, high systolic pressure, high heart rate, recurrent stroke, and fibrinogen level $\geq 400 \mathrm{mg} / \mathrm{dL}$ [8]. The incidence rate of recurrent stroke was 11\% 1 year after a previous stroke and was associated with death in $80 \%$ of cases. In Burkina Faso, previous studies reported a proportion of $15.1 \%$ of strokes among admissions for cardiovascular causes and $52.1 \%$ of strokes among hospitalizations in the neurology department $[9,10]$. The case fatality was estimated at $31.6 \%$ in these hospitals. Kpoda et al. [11] noted an increase number of consultations and hospitalizations for stroke in public hospitals, with a reduction of stroke-related lethality. However, few data exist on the factors associated with hospital stroke lethality in Burkina Faso. The objective of this study was to identify prognostic factors of hospital lethality of stroke cases admitted to the Sourô Sanou University Teaching Hospital (CHUSS) in Burkina Faso.

\section{Materials and Methods}

We conducted a retrospective cohort study in the CHUSS in Burkina Faso. The CHU Souro Sanou is one of the tertiary hospitals (3rd reference level) in the Burkina Faso health pyramid. The theoretical capacity of the hospital is 640 beds with a staff of 1,029 agents all categories combined. Our study was conducted in the neurology department.

Adult patients $>18$ years of age admitted to hospital for stroke between January 1, 2009, and December 31, 2013, were included. The diagnosis of stroke was confirmed by CT [12]. Data were collected from hospitalization and patient medical records. Data (age in years categorized in $<45$ vs. $\geq 45$ years, sex, residence, marital status, socioeconomic level), health safeguarding behavior data (smoker, alcohol consumer), clinical data (consultation time in $<12$ vs. $\geq 12 \mathrm{~h}$, general condition, high blood pressure, state of consciousness, major neurological deficits at entry), personal history hypertension, diabetes, and other cardiovascular diseases were collected. Vital status (deceased or alive) at discharge were our dependent variables. Primary exposure was the type of stroke. Strokes were classified as ischemic or hemorrhagic. Confounding factors were sociodemographic, behavioral, clinical characteristics, and clinical history. For sample size calculation, we considered stroke was classified into hemorrhagic (22\%) and ischemic (78\%) groups based on Labodi et al. [13] study. We estimated the minimum sample size using the Schoenfeld formula [14] for the Cox proportional instantaneous hazards model. The power and significance level were $5 \%$ and $80 \%$, respectively, for the two-tailed test. According to our assumptions, the total number of events (deaths during hospitalization) needed was equal to 95 . The minimum sample size required was then calculated using a proportion of deaths of $40 \%$, intermediate between the proportions observed in two studies performed in Burkina $[9,10]$. The minimum total number of stroke patients needed to be included in our study was 238 .

\section{Sample Size}

During the study period, the total number of stroke cases hospitalized at the CHUSS was 967, of which 312 cases were confirmed by a brain scan. Nineteen stroke cases were not included in survival analyses because their length of hospitalization or vital status at discharge was unknown (Fig. 1).

\section{Statistical Methods}

Each questionnaire was double-checked before entered into an EPIDATA 3.1 database. A descriptive analysis of data was performed. The $\chi^{2}$ test or Fisher's exact test was used to compare proportions. Survival durations were estimated according to the stroke type by the Kaplan-Meier method. The survival curve of the ischemic group was compared to the hemorrhagic one using the log-rank test. Associations between death during hospitalization and independent variables were analyzed using Cox regression. Crude hazard ratios (HRs) and their confidence intervals were calculated. A multivariable Cox model was constructed, using a backward variable selection procedure. The models were validated using the Schoenfeld residual-based test and graphical method. The analyses were performed using Stata version 14 software and significance level used was $5 \%$.

\section{Results}

\section{Description of Stroke Patients Discharge Mode}

In our sample $(n=312)$, the death rate was $27.6 \%$, and patients discharged alive with and without sequelae represented $56.1 \%$ and $9.6 \%$, respectively. For 12 patients (3.9\%), the discharge status was unknown, 7 patients (2.2\%) were discharged against medical advice, and 2 $(0.6 \%)$ were transferred. The distribution of patient discharge status by the stroke type is shown in Figure 2. Lethality was higher in hemorrhagic stroke than in ischemic one (35.8\% vs. $22.4 \%)$, whereas the percentage of discharges with sequelae was higher in ischemic stroke (59.9\% vs. $50.0 \%$ ). The difference in distribution of discharge mode between ischemic and hemorrhagic stroke was not statistically significant $(p=0.091)$. We performed survival analysis for 293 subjects. 


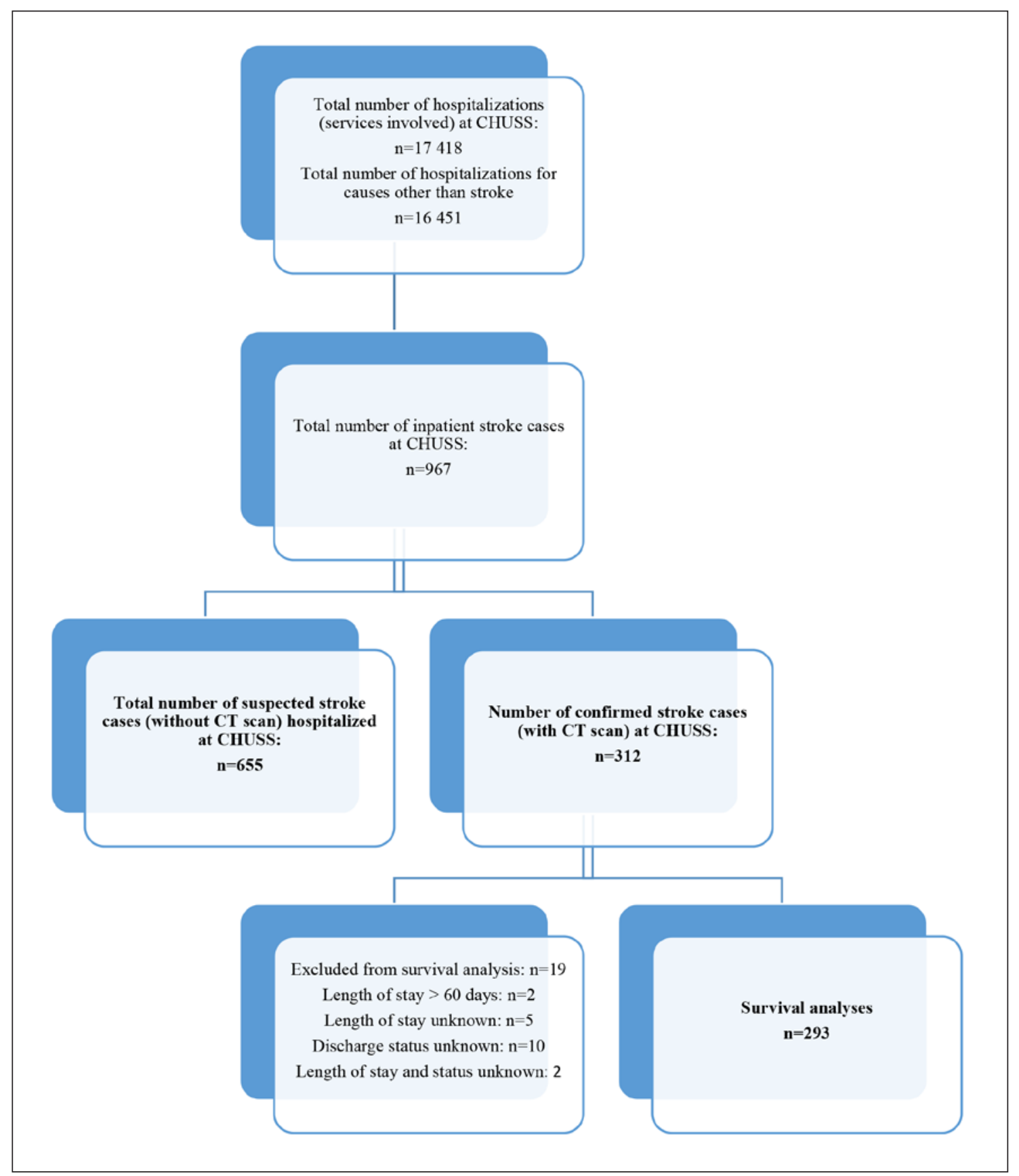

Fig. 1. Flowchart of adult patients admitted to the CHUSS for stroke (2009-2013).

\section{Description of Sociodemographic and Clinical}

\section{Characteristics at Admission}

Our study population was predominantly male, greater than 45 years, and residing in urban areas (Table 1). There were no statistically significant differences between the characteristics of patients with ischemic or hemorrhagic stroke except for occupation. The proportion of civil servants was significantly higher among ischemic stroke patients, whereas the proportions of shopkeepers/ artisans and housewives/workers/retirees were higher among hemorrhagic stroke patients. Most patients consulted more than $12 \mathrm{~h}$ after the onset of the seizure. This proportion was statistically higher in patients with ischemic stroke $(p<0.001)$. At admission, more than $70 \%$ of 


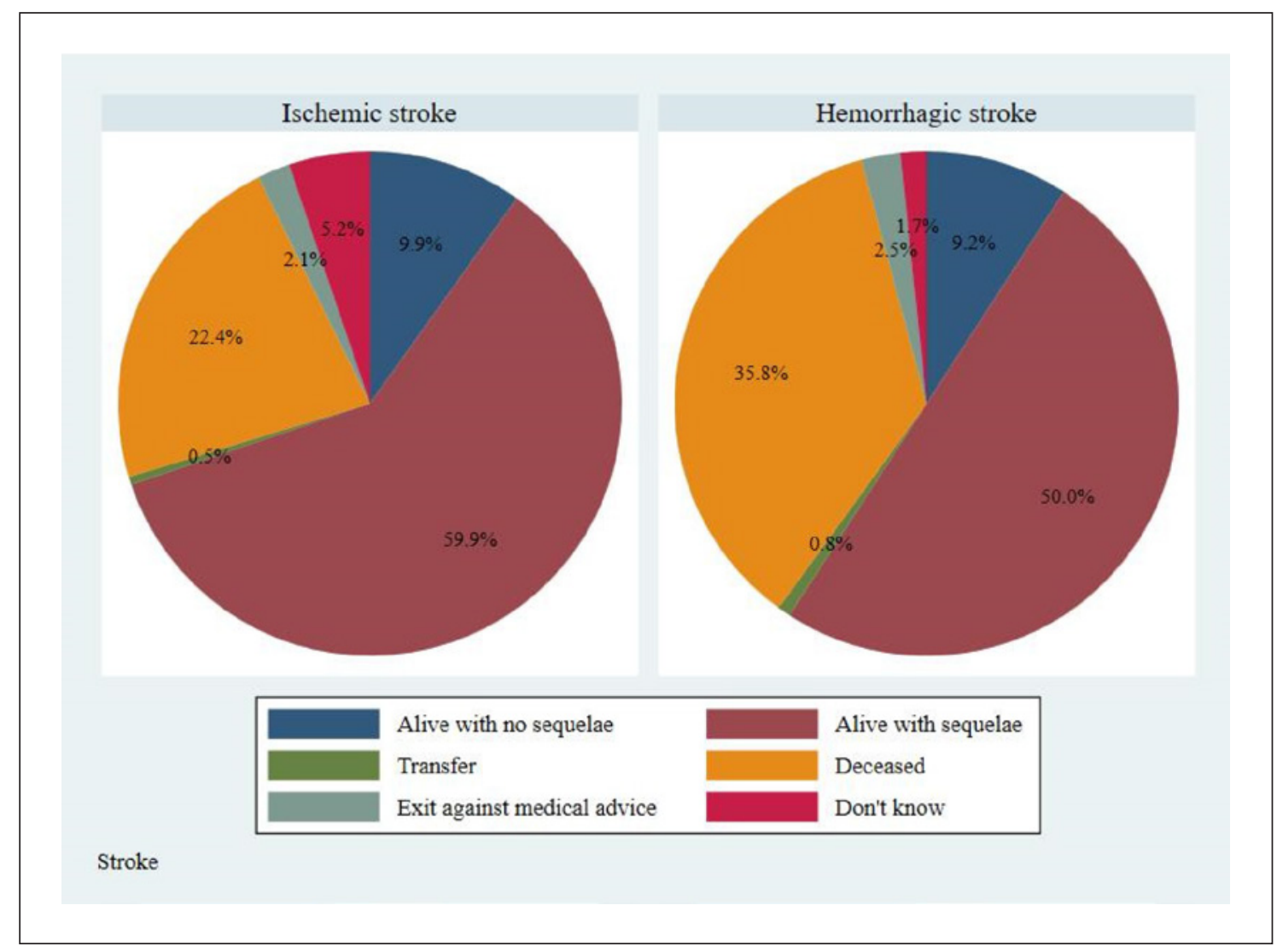

Fig. 2. Distribution of patients hospitalized for stroke from 2009 to 2013 by the stroke type and mode of discharge.

patients had aphasia. Central facial paralysis was present in $40 \%$ of patients, and this proportion was significantly higher in patients with ischemic stroke (46 vs. $31 \%$ ). A stroke history was found in our sample, with a statistically higher proportion in the ischemic stroke group $(p<$ $0.017)$. The main clinical signs at admission were hypertension and the level of consciousness alteration. This proportion was statistically higher in the ischemic stroke group (Table 2).

\section{Mortality by Stroke Type, Sociodemographic and \\ Clinical Characteristics at Admission}

Among the 293 patients included in survival analysis, there were 86 deaths, representing a mortality rate of $29.4 \%$ (CI 95\%: $24.2-34.9 \%$ ) and a mortality rate of 22.2 (17.7-27.4) per 1,000 patients $\times$ days. Survival during hospitalization by the lesion type is shown in Figure 3. Median survival was higher in ischemic stroke patients than in hemorrhagic one (36 and 25 days, respectively), and the two curves differed significantly $(p<0.001)$. In the univariate analysis, the following factors were associated with case fatality at the threshold of $20 \%$ : gender, marital status, socioeconomic level, general condition at entry, type of stroke, level of consciousness, and central facial paralysis (Tables 3,4). There was a significantly higher risk of death in unmarried individuals $(p=0.030)$ and significantly lower risk of death in individuals with low socioeconomic status $(p=0.021)$. According to clinical characteristics, the risk of death was significantly higher in patients with bad condition at entry $(p=0.008)$ and in the presence of consciousness alteration $(p=$ 0.003). The instantaneous risk of death in hemorrhagic stroke was 2.14 (CI 95\%: 1.37-3.33) times higher than in ischemic stroke $(p=0.001)$. In multivariable model established on the basis of clinical characteristics, a significantly higher risk of death was observed in the presence of altered consciousness, central facial paralysis, and hemorrhagic stroke (a HR [CI 95\%]: 2.25 [1.41-3.61]) (Table 5). 
Table 1. Sociodemographic and lifestyle characteristics by the stroke type

\begin{tabular}{|c|c|c|c|c|}
\hline \multirow[t]{2}{*}{ Variables } & \multirow[t]{2}{*}{ Total } & \multicolumn{3}{|c|}{ Stroke type } \\
\hline & & IS & HS & $p$ value $^{\dagger}$ \\
\hline \multicolumn{5}{|l|}{ Age } \\
\hline$N$ & 292 & 176 & 116 & \multirow{2}{*}{0.381} \\
\hline$\geq 45$ years, $\%$ & 89.0 & 90.3 & 87.1 & \\
\hline \multicolumn{5}{|l|}{ Gender } \\
\hline$N$ & 291 & 175 & 116 & \multirow{2}{*}{0.156} \\
\hline Male, \% & 65.0 & 61.7 & 69.8 & \\
\hline \multicolumn{5}{|l|}{ Residence } \\
\hline$N$ & 235 & 142 & 93 & \multirow{2}{*}{0.443} \\
\hline Urban, \% & 73.6 & 71.8 & 76.3 & \\
\hline \multicolumn{5}{|l|}{ Marital status } \\
\hline$N$ & 139 & 84 & 55 & \multirow{2}{*}{0.881} \\
\hline Married, \% & 84.9 & 84.5 & 85.5 & \\
\hline \multicolumn{5}{|l|}{ Socioeconomic level } \\
\hline$N$ & 132 & 72 & 60 & \multirow[t]{2}{*}{0.443} \\
\hline Low, \% & 65.2 & 68.1 & 61.7 & \\
\hline \multicolumn{5}{|l|}{ Profession } \\
\hline$N$ & 111 & 60 & 51 & \multirow{5}{*}{0.020} \\
\hline Civil servant, \% & 16.2 & 23.3 & 7.8 & \\
\hline Individual/merchant/artisan (e), \% & 19.8 & 15.0 & 25.5 & \\
\hline Cultivator, \% & 32.4 & 38.3 & 25.5 & \\
\hline Housewife/worker/retired, \% & 31.5 & 23.3 & 41.2 & \\
\hline \multicolumn{5}{|l|}{ Tobacco } \\
\hline$N$ & 106 & 72 & 34 & \multirow{2}{*}{0.753} \\
\hline Yes, \% & 21.7 & 20.8 & 23.5 & \\
\hline \multicolumn{5}{|l|}{ Alcohol } \\
\hline$N$ & 112 & 74 & 38 & \multirow{2}{*}{0.257} \\
\hline Yes, \% & 37.5 & 33.8 & 44.7 & \\
\hline
\end{tabular}

\section{Discussion}

In this study, we considered only $32.3 \%$ of patients admitted for stroke whose diagnosis were confirmed with a brain CT scan. Prognostic factors independently associated with lethality were type of stroke, hemorrhagic stroke, altered state of consciousness, and central facial paralysis. A patient with hemorrhagic stroke has a higher risk of death because of the vascular rupture leading very quickly to hydroelectrolytic and hemodynamic disorders. Also, the management is different which means that if diagnosis is not made early, death occurs quickly. Fatality was significantly two times higher in patients with hemorrhagic stroke than ischemic stroke. This high lethality could be explained by the delay in performing brain CT scans, the management depending on type of lesions. This high mortality in the hemorrhagic group corroborated finding of other studies [15-17] which indicates the severity of hemorrhagic types, especially in resource-constrained countries. Indeed, in hemorrhagic stroke, there are often neurological complications such as acute intracranial hypertension syndrome. In addition, depending on hematoma volume, cerebral involvement with a mass effect can occurs. The presence of hypertension in hemorrhagic stroke made often its control difficult. Finally, hematoma location also has an impact, i.e., location in posterior fossa of brain worsens the prognosis. The predominance of ischemic stroke in our sample is similar to that of Dabilgou et al. [31], Ouedraogo et al. [16], Labodi et al. [17], Kaduka et al. [15], and Jowi and Mativo [18] in Kenya. On the contrary, in Nigeria, a study noted a predominance of hemorrhagic stroke which could be related to the recruitment of patients with a coma, which was much more common in hemorrhagic. Furthermore, they showed that age, male gender, the presence of hypertension, and comorbidity were determinants of poor prog-
40

Cerebrovasc Dis Extra 2022;12:36-46 DOI: $10.1159 / 000523888$
Kpoda et al. 
Table 2. Clinical and biological characteristics by the stroke type - CHUSS stroke inpatients (2009-2013)

\begin{tabular}{|c|c|c|c|c|}
\hline Variable & Total & $\begin{array}{l}\text { Ischemic } \\
\text { stroke }\end{array}$ & $\begin{array}{l}\text { Hemorrhagic } \\
\text { stroke }\end{array}$ & $p$ value $^{\dagger}$ \\
\hline \multicolumn{5}{|l|}{ Consultation time } \\
\hline$N$ & 209 & 127 & 82 & \multirow{2}{*}{$<0.001$} \\
\hline$\geq 12 \mathrm{~h}, \%$ & 62.7 & 72.4 & 47.6 & \\
\hline \multicolumn{5}{|c|}{ General condition at entry } \\
\hline$N$ & 287 & 173 & 114 & \multirow{2}{*}{0.323} \\
\hline Bad, \% & 33.5 & 31.2 & 36.8 & \\
\hline \multicolumn{5}{|l|}{ Reported history } \\
\hline HBP & & & & \\
\hline$N$ & 283 & 172 & 111 & \multirow{2}{*}{0.305} \\
\hline Yes, \% & 68.6 & 66.3 & 72.1 & \\
\hline \multicolumn{5}{|l|}{ Diabetes } \\
\hline$N$ & 243 & 149 & 94 & \multirow{2}{*}{0.405} \\
\hline Yes, \% & 8.2 & 9.4 & 6.4 & \\
\hline \multicolumn{5}{|l|}{ Stroke } \\
\hline$N$ & 231 & 146 & 85 & \multirow{2}{*}{0.017} \\
\hline Yes, \% & 18.6 & 23.3 & 10.6 & \\
\hline \multicolumn{5}{|l|}{ State of consciousness } \\
\hline \multicolumn{5}{|l|}{ HBP } \\
\hline$N$ & 270 & 163 & 107 & \multirow{2}{*}{$<0.001$} \\
\hline Yes, \% & 80.0 & 73.0 & 90.7 & \\
\hline \multicolumn{5}{|c|}{ State of consciousness } \\
\hline$N$ & 286 & 172 & 114 & \multirow{2}{*}{0.004} \\
\hline Abnormal, \% & 35.7 & 29.1 & 45.6 & \\
\hline \multirow{2}{*}{\multicolumn{5}{|c|}{$\begin{array}{l}\text { Major neurological deficit } \\
\text { Language }\end{array}$}} \\
\hline & & & & \\
\hline$N$ & 195 & 122 & 73 & \multirow[b]{2}{*}{0.608} \\
\hline Aphasia, \% & 73.3 & 74.6 & 71.2 & \\
\hline \multicolumn{5}{|c|}{ Central facial paralysis } \\
\hline$N$ & 285 & 171 & 114 & \multirow{2}{*}{0.009} \\
\hline Yes, $\%$ & 40.0 & 46.2 & 30.7 & \\
\hline
\end{tabular}

nosis [19]. Hypertension was not found to be a prognostic factor in our study. This can be explained by the fact that some patients were already under treatment, or blood pressure measurement was mostly done after the antihypertensive medication was taken. The delay in consultation could also be due to the fact that most patients do not respect or are not aware of country's health system functioning and therefore often end up consulting at a level of care which is not appropriate for their pathology. The higher median survival in ischemic stroke indicates and highlights the interest in early detection and timely CT scanning that increase the chances of patients' survival. Indeed, the result of the CT scan points out the type of stroke and determines the type of medical treatment to be administered. So, the earlier it is done, the better the patient's chance of recovery. Moreover, the alteration of consciousness is also an element of bad prognosis because the management is delicate often requiring the installation of a nasogastric tube and a very strict monitoring of the vital constants in a reanimation ward. In fact, patients with impaired consciousness have a higher risk of death. Our results are similar to findings in Saudi Arabia. In addition, they found that a history of hypertension and smoking were prognostic factors for stroke death [20]. The management of these patients is even more delicate because there is frequently pulmonary fragility leading to body poor oxygenation. History of hypertension also leads to acute lung edema, which can quickly lead to death. However, no association with history of hypertension could be explained by the follow-up problem and even a lack of knowledge of their status in Africa. The presence of altered consciousness had a strong influence on lethality if we consider the type of stroke, which is consistent with clinical practice. This is the same line with the 
Fig. 3. Survival during hospitalization by the stroke type (Kaplan-Meier curve and log-rank tests) - patients hospitalized for stroke at the CHUSS (2009-2013).

Table 3. Mortality by sociodemographic and lifestyle characteristics (univariate Cox model) - CHUSS stroke inpatients (20092013)

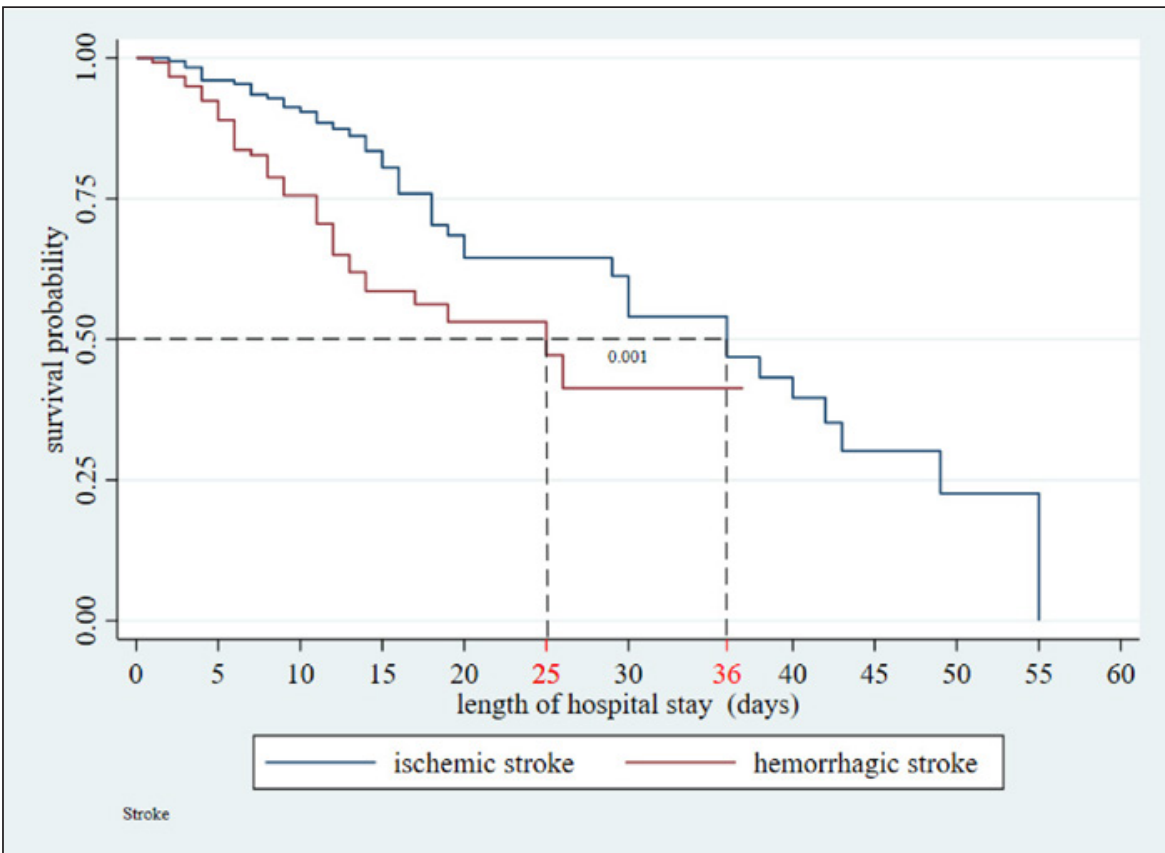

\begin{tabular}{|c|c|c|c|c|}
\hline Variables & $N$ & $\begin{array}{l}\text { Mortality rate (per } \\
1,000 \text { patients } \times \text { days) }\end{array}$ & $\begin{array}{l}\text { Crude HR } \\
(\mathrm{Cl} 95 \%)\end{array}$ & $p$ value $^{\dagger}$ \\
\hline \multicolumn{5}{|l|}{ Age } \\
\hline $15-44$ years & 32 & 13.8 & 1 & \multirow{2}{*}{0.349} \\
\hline$\geq 45$ years & 260 & 22.8 & $1.54[0.62-3.82]$ & \\
\hline \multicolumn{5}{|l|}{ Gender } \\
\hline Female & 102 & 17.2 & 1 & \multirow{2}{*}{0.140} \\
\hline Male & 189 & 25.0 & $1.43[0.89-2.31]$ & \\
\hline \multicolumn{5}{|l|}{ Residence } \\
\hline Rural & 62 & 19.0 & 1 & \multirow{2}{*}{0.303} \\
\hline Urban & 173 & 24.0 & $1.35[0.76-2.40]$ & \\
\hline \multicolumn{5}{|l|}{ Marital status } \\
\hline Married & 118 & 16.6 & 1 & \multirow{2}{*}{0.030} \\
\hline Single/divorced/widowed & 21 & 35.2 & $2.45[1.09-5.52]$ & \\
\hline \multicolumn{5}{|c|}{ Socioeconomic level } \\
\hline Low & 86 & 15.3 & 1 & \multirow{2}{*}{0.021} \\
\hline High or average & 46 & 32.5 & $2.2[1.12-4.35]$ & \\
\hline \multicolumn{5}{|l|}{ Profession } \\
\hline Civil servant & 18 & 10.9 & 1 & \multirow{4}{*}{0.091} \\
\hline Merchant/craftsman & 22 & 26.3 & $2.23[0.46-10.79]$ & \\
\hline Cultivator & 36 & 13.3 & $0.80[0.16-4.17]$ & \\
\hline Housewife/other & 35 & 31.7 & $2.80[0.63-12.57]$ & \\
\hline \multicolumn{5}{|l|}{ Lifestyle } \\
\hline \multicolumn{5}{|l|}{ Smoker } \\
\hline No & 83 & 20.4 & 1 & \multirow{2}{*}{0.781} \\
\hline Yes & 23 & 20.8 & $1.14[0.45-2.86]$ & \\
\hline \multicolumn{5}{|l|}{ Alcohol consumption } \\
\hline No & 70 & 18.5 & 1 & \multirow{2}{*}{0.397} \\
\hline Yes & 42 & 25.5 & 1.39 [0.65-2.99] & \\
\hline
\end{tabular}

${ }^{\dagger} p$ value, Wald test. 
Table 4. Mortality according to clinical characteristics at the CHUSS (2009-2013) (univariate Cox model)

\begin{tabular}{|c|c|c|c|c|}
\hline Variables & $N$ & $\begin{array}{l}\text { Mortality rate } \\
\text { (per } 1,000 \text { patients } \\
\times \text { days) }\end{array}$ & $\begin{array}{l}\text { Crude HR } \\
\text { (Cl 95\%) }\end{array}$ & $p$ value $^{\dagger}$ \\
\hline \multicolumn{5}{|l|}{ Time to consultation } \\
\hline$<12 \mathrm{~h}$ & 78 & 25.3 & 1 & \multirow{2}{*}{0.416} \\
\hline$\geq 12 \mathrm{~h}$ & 131 & 21.5 & $0.81[0.49-1.34]$ & \\
\hline \multicolumn{5}{|l|}{ General condition at entry } \\
\hline Good & 191 & 17.2 & 1 & \multirow{2}{*}{0.008} \\
\hline Bad & 96 & 31.0 & $1.79[1.16-2.75]$ & \\
\hline \multicolumn{5}{|l|}{ Reported history } \\
\hline \multicolumn{5}{|l|}{$\mathrm{HBP}$} \\
\hline No & 89 & 25.3 & 1 & \multirow{2}{*}{0.444} \\
\hline Yes & 194 & 19.6 & $0.83[0.52-1.34]$ & \\
\hline \multicolumn{5}{|l|}{ Diabetes } \\
\hline No & 223 & 22.4 & 1 & \multirow{2}{*}{0.715} \\
\hline Yes & 20 & 25.2 & $1.15[0.55-2.41]$ & \\
\hline \multicolumn{5}{|l|}{ Stroke } \\
\hline No & 188 & 21.5 & 1 & \multirow{2}{*}{0.499} \\
\hline Yes & 43 & 18.4 & $0.79[0.40-1.56]$ & \\
\hline \multicolumn{5}{|l|}{ Clinical signs at entry } \\
\hline HBP & & & & \\
\hline No & 54 & 20.2 & 1 & \multirow[b]{2}{*}{0.865} \\
\hline Yes & 216 & 20.9 & $1.05[0.59-1.86]$ & \\
\hline \multicolumn{5}{|l|}{ Type of stroke } \\
\hline Ischemic & 176 & 17.1 & 1 & \multirow{2}{*}{0.001} \\
\hline Hemorrhagic & 117 & 31.4 & 2.14 [1.37-3.33] & \\
\hline \multicolumn{5}{|l|}{ State of consciousness } \\
\hline Normal & 184 & 15.6 & 1 & \multirow{2}{*}{0.003} \\
\hline Altered & 102 & 32.7 & $1.95[1.25-3.04]$ & \\
\hline \multirow{2}{*}{\multicolumn{5}{|c|}{$\begin{array}{l}\text { Major neurological deficit } \\
\text { Lanquage }\end{array}$}} \\
\hline & & & & \\
\hline Normal & 52 & 15.3 & 1 & \multirow{2}{*}{0.425} \\
\hline Dysarthria/Aphasia & 143 & 21.5 & $1.32[0.66-2.68]$ & \\
\hline \multicolumn{5}{|l|}{ Central facial paralysis } \\
\hline No & 171 & 19.8 & 1 & \multirow{2}{*}{0.137} \\
\hline Yes & 114 & 24.6 & $1.42[0.89-2.25]$ & \\
\hline
\end{tabular}

Labodi et al. [17] study. In addition, a Nigerian study showed that altered consciousness is a poor prognostic factor apart from the presence of comorbidity and a high NIHSS score. Finally, the presence of central facial paralysis is also pejorative and aggravates the clinical outcomes since it is part of the hemiplegia syndrome found in the hemorrhagic type with poor prognosis. Therefore, its presence deserves special attention in terms of management. The neurological deficit especially the language disorders reported in our series has been highlighted by other authors such as Labodi et al. [17] and Pavaloiu and Mogoanta [21]. Each factor individually has an important role in lethality. When we combine these three factors, we find a significant association between the type of stroke, state of consciousness, and facial paralysis with death which effectively shows the severity of this disease and further potentiates lethality. Therefore, the presence of these factors indicates emergency not only in the early diagnosis but also in the adequate management of patients as well. A study carried out in Tunisia found similarities with our data but reported other factors such as the NIHSS score, mydriasis, aphasia. This was a prospective study so the authors had been able to control the variables at the beginning of study [22]. There is therefore a crucial need for continuous monitoring to increase the chances of survival for patients. The overall lethality of $27.6 \%$ showed that stroke is still a public health problem in our context. It could be explained by a lack of aware- 
Table 5. Association between clinical characteristics and occurrence of death during hospitalization (multivariable Cox) $(n=280$, 80 deaths) - patients hospitalized for stroke at the CHUSS (20092013)

\begin{tabular}{lll}
\hline Variable & Adjusted HR (Cl 95\%) & $p$ value $^{\dagger}$ \\
\hline $\begin{array}{l}\text { Stroke type } \\
\text { Ischemic } \\
\quad \text { Hemorrhagic }\end{array}$ & 1 & \\
$\begin{array}{l}\text { State of consciousness } \\
\quad \text { Normal }\end{array}$ & $2.25[1.41-3.61]$ & 0.001 \\
$\quad \begin{array}{l}\text { Altered } \\
\text { Central facial paralysis } \\
\quad \text { No }\end{array}$ & 1 & \\
$\quad$ Yes & $1.90[1.20-2.99]$ & 0.006 \\
\hline
\end{tabular}

Eliminated from the Cox model because NS: general condition at entry. Variables not considered for the multivariable model $(p>$ 0.20 in univariate analysis): time to consultation, history of hypertension, diabetes, stroke, hypertension at entry, and language. ${ }^{\dagger} p$ value, Wald test.

ness on the risk factors and of the seriousness of this disease by the population. Therefore, they lose time before consulting a doctor. This may be a problem of diagnosis and management in some health facilities. This lethality is comparable to other studies results such as those from Burkina Faso, Mozambique, and in France [7, 16, 17, 23]. Indeed, a systematic review of the literature has shown that in hospital studies, case fatality is between 27 and $46 \%$ in Africa [5]. However, our result is greater than the finding of N'Goran et al. [24] in Abidjan, Dabilgou et al. [31], and Lompo et al. [25] in Burkina Faso. This difference could be explained by the fact that we used 5 years of data from all departments that received stroke cases, compared to only emergency ward data used by N'Goran. The small sample size, which was limited to neurology department and included only patients over 65 years of age, seems to explain Dabilgou et al.'s study. The difference with Labodi is related to the fact that the author only included patients with ischemic stroke where generally the lethality is low. In Africa, the level of technical facilities performance in hospitals differs from country to country, explaining some of the observed disparity in mortality rates. The comforting results recorded in developed countries relate to the improvement of access to quality care for the management of strokes, in particular the timely transport of patients, medical interventions based on evidence such as thrombolysis of acute cerebral ischemia, and high-quality specialized facilities such as dedicated stroke units [26]. Conversely, in SSA, the high rates of early mortality observed are thought to be the result of delays in admission and management of patients with stroke, the absence of stroke units, or fibrinolysis yet the only therapeutic strategies of proven effectiveness [27]. These dysfunctions could be explained by the weakness of African health systems, marked among other things by the insufficiency in the primary prevention of strokes, the low availability, and/or the low accessibility of medico-technical equipment, the insufficiency of qualified human resources [28]. However, in developed countries and some emerging countries, the improvement in access to quality care for the management of strokes, the timely transport of patients to stroke units, interventions, and evidence-based medicine such as controlling the expansion of the volume of ICH by early and rapid reduction in the relapse of hypertension allowed a significant reduction in early mortality [29]. On the contrary, Burkina Faso and in certain other countries of SSA was recorded an increase in death rates from hemorrhagic stroke, adjusted according to age, between 1990 and 2010 [30].

Our study has some limitations. First, data used for our analysis were not originally collected for research purposes. This results in a high proportion of missing data. The lack of archiving and the handwritten system use may have led to the nonexhaustiveness of hospitalized cases. The precision and accuracy of the information may have been reduced by the nonstandardization of measurements by different categories of health workers at different times. Nevertheless, our study had a sufficient sample size to compare mortality according to the type of stroke.

\section{Recommendations}

For research, the determinants of stroke lethality should be confirmed in subsequent prospective observational studies with a larger sample of patients; for public health, to raise public awareness through information and communication technologies about the recognition of stroke warning signs, control of cardiovascular risk factors, and needs for early management; and at the clinical level, to develop strategies to strengthen the skills of health personnel in the diagnosis and early management of stroke cases.

\section{Conclusion}

Our study revealed a high mortality rate in Burkinabe stroke patients. The hemorrhagic form, the state of consciousness, and the central facial paralysis are the main independent prognostic factors. Our results highlighted
Kpoda et al. 
the need to develop and implement effective prevention strategies and management in Africa. Rigorous monitoring was performed with good management of high-risk patients, improving access to quality management of stroke. The creation of intensive care units will also contribute to the reduction of stroke mortality. Future largescale prospective national studies is needed to better appreciate the magnitude and determinants of stroke.

\section{Acknowledgments}

We thank Mr. Mogokélenfatè Sagnon and Dr. Abdul Gafar Victoir Coulidiaty for providing language help. The Belgium' cooperation for my $\mathrm{PhD}$ program scholarship.

\section{Statement of Ethics}

Administrative authorization was obtained from the heads of departments of the CHUSS. This retrospective review of patient data did not require ethical approval in accordance with local/national guidelines. Written informed consent from participants was not required in accordance with local/national guidelines. After the study, all data were stored in secure rooms and only accessible to research staff. Nevertheless, the variables were collected confidentially without patient identification.

\section{Conflict of Interest Statement}

The authors have no conflicts of interest to declare.

\section{Funding Sources}

We received scholarship from the Belgium cooperation (CCCI16/051) for our PhD program.

\section{Author Contributions}

H.B.N.K.: concept, design, analysis, and drafting. L.G.B.S.: design and reviewing; D.R.S.S.: data collection; S.M.A.S.: analysis and reviewing; I.T.T., I.S., A.M., and D.L.: manuscript reviewing; and M.D. and P.D.: design, analysis, and reviewing. All the authors: final approval.

\section{Data Availability Statement}

All data generated or analyzed during this study are included in this article. Further inquiries can be directed to the corresponding author.

\section{References}

1 Feigin VL, Forouzanfar MH, Krishnamurthi R, Mensah GA, Connor M, Bennett DA, et al. Global and regional burden of stroke during 1990-2010: findings from the Global Burden of Disease Study 2010. Lancet. 2014 Jan 18; 383(9913):245-54.

2 Urimubenshi G, Cadilhac DA, Kagwiza JN, $\mathrm{Wu} \mathrm{O}$, Langhorne P. Stroke care in Africa: a systematic review of the literature. Int J Stroke. 2018 Oct;13(8):797-805.

3 Feigin VL. Stroke epidemiology in the developing world. Lancet. 2005 Jul 25;365(9478): 2160-1.

4 Kengne AP, Anderson CS. The neglected burden of stroke in Sub-Saharan Africa. Int Stroke. 2006;1(4):180-90.

5 Owolabi MO, Akarolo-Anthony S, Akinyemi R, Arnett D, Gebregziabher M, Jenkins C, et al. The burden of stroke in Africa: a glance at the present and a glimpse into the future. Cardiovasc J Afr. 2015 Apr;26(2 Suppl 1):S27-38.

6 Sarfo FS, Acheampong JW, Appiah LT, Oparebea E, Akpalu A, Bedu-Addo G. The profile of risk factors and in-patient outcomes of stroke in Kumasi, Ghana. Ghana Med J. 2014 Sep;48(3):127-34.
7 Gomes J, Damasceno A, Carrilho C, Lobo V, Lopes H, Madede T, et al. Determinants of early case-fatality among stroke patients in Maputo, Mozambique and impact of in-hospital complications. Int J Stroke. 2013 Oct;8 Suppl A100:69-75.

8 Longo-Mbenza B, Tonduangu K, Muyeno K, Phanzu M, Kebolo Baku A, Muvova D, et al. Predictors of stroke: associated mortality in Africans. Rev Epidemiol Sante Publique. 2000 Jan;48(1):31-9.

9 Napon C, Kaboré A, Ouédraogo M, Dravé A, Lompo L, Kaboré J. [Strokes and hemoglobinopathies in Burkina Faso]. Med Sante Trop. 2012 Oct 12;22(4):390-3.

10 Zabsonre P, Yameogo A, Millogo A, Dyemkouma FX, Durand G. [Risk and severity factors in cerebrovascular accidents in West African Blacks of Burkina Faso]. Med Trop. 1997;57(2):147-52.

11 Kpoda HB, Savadogo LG, Lemogoum D, Somda S, Sombié I, Dramaix MW, et al. Stroke among the adult population of Burkina Faso: magnitude and trend. J Xiangya Med. 2019;4:15.

12 Krainik A, Villien M, Troprès I, Attyé A, Lamalle L, Bouvier J, et al. Functional imaging of cerebral perfusion. Diagn Interv Imaging. 2013 Dec;94(12):1259-78.
13 Labodi LD, Aziz DB, Ousséini D, Mariam OA, Lassina K, Christian N, et al. Hospitalized patients care pathway for stroke and its determinants in a Reference Hospital in Ouagadougou (Burkina Faso). 2017.

14 Schoenfeld DA. Sample-size formula for the proportional-hazards regression model. Biometrics. 1983;39(2):499-503.

15 Kaduka L, Korir A, Oduor CO, Kwasa J, Mbui J, Wabwire S, et al. Stroke distribution patterns and characteristics in Kenya's leading Public Health Tertiary Institutions: Kenyatta National Hospital and Moi Teaching and Referral Hospital. Cardiovasc J Afr. 2018 Apr; 29(2):68-72.

16 Ouedraogo PV, Savadogo AA, Samadoulougou S, Millogo A, Héma A. Mortalite des accidents vasculaires cerebraux a la phase aigüe au centre Hospitalier Universitaire Souro Sanou Bobo-Dioulasso; Burkina Faso. Afr J Neurol Sci. 2019;38(2):22-9.

17 Labodi LD, Kadri C, Valentin YN, Christian N, Jean KB. Intra-hospital mortality of stroke and its predictive factors in a Reference Hospital in Ouagadougou, Burkina Faso. Brain. 2017;1(3):1-6. 
18 Jowi JO, Mativo PM. Pathological sub-types, risk factors and outcome of stroke at the Nairobi Hospital, Kenya. East Afr Med J. 2008; 85(12):572.

19 Obiako OR, Oparah SK, Ogunniyi A. Prognosis and outcome of acute stroke in the University College Hospital Ibadan, Nigeria. Niger J Clin Pract. 2011;14(3):359-62.

20 Alhazzani AA, Mahfouz AA, Abolyazid AY, Awadalla NJ, Katramiz K, Faraheen A, et al. In hospital stroke mortality: rates and determinants in Southwestern Saudi Arabia. Int J Environ Res Public Health. 2018;15(5):927.

21 Pavaloiu R, Mogoanta L. Clinical, epidemiological and etiopathogenic study of ischemic stroke. Curr Health Sci J. 2017 Sep;43(3):25862.

22 Moalla KS, Damak M, Chakroun O, Farhat N, Sakka S, Hdiji O, et al. Facteurs pronostiques de mortalité par accident vasculaire cérébral artériel à la phase aiguë dans une population nord-africaine. Pan Afr Med J. 2020;35:50.
23 Guilhermet Y, Valdelièvre L, Krolak-Salmon P. L'AVC du sujet âgé: vers une prise en charge spécialisée à la phase aiguë et en SSR. Cah Année Gérontol. 2010 Jun 1;2(2):97-103.

24 N'Goran YNK, Traore F, Tano M, Kramoh KE, Kakou J-BA, Konin C, et al. [Epidemiological aspects of stroke at emergencies services of Abidjan Heart Institute]. Pan Afr Med J. 2015;21:160.

25 Lompo DL, Cissé K, Diallo O, Kouanda B, Napon C, Kaboré BJ. Facteurs de risque de mortalité intrahospitalière après infarctus cérébral au Burkina Faso. Neurol Psychiatr Gériatr. 2018;18(108):348-54.

26 Organisation for Economic Co-Operation and Development. Cardiovascular disease and diabetes: policies for better health and quality of care. OECD Publishing; 2015.

27 Connor MD, Walker R, Modi G, Warlow CP. Burden of stroke in black populations in SubSaharan Africa. Lancet Neurol. 2007;6(3): 269-78.
28 Owolabi MO, Bower JH, Ogunniyi A. Mapping Africa's way into prominence in the field of neurology. Arch Neurol. 2007;64(12): 1696-700.

29 Bragado-Trigo I, Portilla-Cuenca JC, FalconGarcia A, Fermin-Marrero JA, Romero-Sevilla RM, Redondo-Penas MI, et al. [The impact of neurological and medical complications on the mortality and functional situation of acute stroke patients]. Rev Neurol. 2014;59(10): 433-42.

30 Kaduka L, Muniu E, Oduor C, Mbui J, Gakunga R, Kwasa J, et al. Stroke mortality in Kenya's Public Tertiary Hospitals: a prospective facility-based study. Cerebrovasc Extra. 2018; 8(2):70-9.

31 Dabilgou AA, et al. Stroke in the elderly in tropical settings: epidemiological, clinical and prognostic aspects. Neurol Psychiatr Gériatr. 2018;18(105):133-9. 